\title{
PENGARUH AKTIVASI KIMIA DENGAN BANTUAN IRADIASI GELOMBANG MIKRO TERHADAP SIFAT FISIS KARBON AKTIF DARI SEKAM PADI SEBAGAI ADSORBEN
}

\author{
Nurlisa Kartikasari ${ }^{1, *}$, Rakhmawati Farma ${ }^{2}$, Awitdrus ${ }^{3}$ \\ ${ }^{1}$ Mahasiswa Program Studi S1 Fisika ${ }^{1}$ \\ ${ }^{2,3}$ Dosen Jurusan Fisika ${ }^{2}$ \\ Fakultas Matematika dan Ilmu Pengetahuan Alam \\ Universitas Riau Kampus Bina Widya \\ J1. Prof. Muchtar Luthfi Pekanbaru, 28293, Indonesia \\ *E-mail: nurlisakartikasari@gmail.com
}

\begin{abstract}
The percentage of $\mathrm{KOH}$ affects the quality of activated carbon. In this research the activated carbon has been made of biomass from rice husk by using the process carbonization, chemical activation using Potassium Hydroxide variated percentage for 5\%,10\%, 15\% and 20\% from the mass of sample and microwave irradiation power by 450 Watt. The surface morphology of activated carbon for the sample KA10 produced the even pores structure and lots of pores more than sample KA5, KA15 and KA20. The analysis results of surface morphology of activated also supported by analysis atomic adsorption spectroscopy (AAS) show that sample KA10 has the highest heavy metal adsorption 92,40\% for $\mathrm{Ni}, 91,31 \%$ for $\mathrm{Pb}$ and 70,24\% for $\mathrm{Zn}$.
\end{abstract}

Keywords : Rice husk, activated carbon, potassium hidroxide, microwave irradiation, adsorption, heavy metals.

\begin{abstract}
ABSTRAK
Persentase aktivator Kalium Hidroksida (KOH) dapat berpengaruh terhadap kualitas karbon aktif. Pada penelitian ini karbon aktif dibuat dari biomassa yang berbahan dasar sekam padi dengan melalui proses pra-karbonisasi, aktivasi kimia dengan menggunakan aktivator $\mathrm{KOH}$ dengan variasi persentase 5\%, 10\%, 15\% dan 20\% dari berat sampel dan iradiasi gelombang mikro dengan daya 450 Watt selama 15 menit. Morfologi permukaan karbon aktif untuk sampel KA10 menghasilkan struktur pori yang lebih teratur dan pori-pori yang lebih banyak daripada sampel KA5, KA15 dan KA20. Hasil analisa morfologi permukaan karbon aktif didukung dengan analisa daya serap karbon aktif yang menunjukkan bahwa sampel KA10 memiliki daya serap logam berat terbesar yaitu 92,40\% untuk $\mathrm{Ni}$, 91,31\% untuk logam $\mathrm{Pb}$ dan 70,24\% untuk logam $\mathrm{Zn}$.
\end{abstract}

Kata Kunci : Sekam padi, karbon aktif, kalium hidroksida, iradiasi gelombang mikro, adsorpsi, logam berat.

\section{PENDAHULUAN}

Laut Indonesia yang sangat luas menjadikan Indonesia sebagai negara bahari dan kepulauan terbesar di dunia dengan potensi pemanfaatan sumber daya laut didalamnya.Seiring pemanfaatan sumber daya laut ini, laut terancam oleh banyaknya tekanan dari aktivitas manusia sehingga menyebabkan air laut menjadi tercemar [1]. Aktivitas industri merupakan salah satu sumber utama pencemaran air laut karena penggunaan logam berat seperti $\mathrm{Ni}, \mathrm{Pb}, \mathrm{Zn}, \mathrm{Cd}$ dan $\mathrm{Cu}$ dalam proses industrinya [2].

Adanya kandungan logam berat pada air laut berbahaya bagi kehidupan organisme dan efeknya secara tidak langsung terhadap kesehatan manusia.Teknik adsorbsi merupakan salah satu metode pengolahan air secara fisika yang dapat digunakan untuk mengurangi kadar logam berat yang terdapat pada air laut. Teknik adsorpsi dapat digunakan untuk menghilangkan bahan-bahan organik atau logam berat terlarut yang tidak diinginkan [3]. Bahan adsorben yang biasa 
digunakan adalah karbon aktif [4]. Sekam padi adalah salah satu yang dapat dijadikan karbon aktif karena sekam padi merupakan limbah biomassa dari hasil olahan pertanian.Sekam merupakan kulit padi yang dihasilkan dari proses penggilingan untuk memisahkan padi dari kulitnya. Sekam padi memiliki kerapatan jenis $1,125 \mathrm{~kg} / \mathrm{m}^{3}$.Sekam padi mempunyai komposisi selulosa yang dapat dikonversikan menjadi karbon [5]. Sekam padi memiliki kandungan unsur karbon sebesar 48,9\% [6].

Berdasarkan uraian latar belakang tersebut maka penelitian ini dilakukan untuk mengetahui pengaruh variasi persentase aktivator kimia terhadap morfologi permukaan dan daya serap karbon aktif yang dihasilkan. Karbon aktif dibuat dari sekam padi diaktivasi kimia dengan variasi persentase $\mathrm{KOH} 5 \%, 15 \%, 20 \%$ dan $20 \%$, kemudian dilakukan iradisi gelombang mikro dengan daya 450 watt. Pengujian dilakukan pada air laut yang berada di daerah Dumai dengan indikator yang diuji yaitu kandungan logam berat diantaranya $\mathrm{Ni}, \mathrm{Pb}$ dan $\mathrm{Zn}$ sebelum dan setelah ditambahkan karbon aktif.

\section{METODE PENELITIAN}

Sekam padi yang digunakan pada penelitian ini adalah sekam padi yang berasal dari persawahan warga kota Payakumbuh, Sumatera Barat. Sekam padi yang sudah didapatkan dilakukan pengayakan untuk memisahkan sekam padi dari sisa-sisa beras. Sekam padi kemudian dijemur dibawah sinar matahari selama 3-4 hari sampai massa sekam padi konstan yang menandakan tidak ada lagi air yang terkandung dalam sekam padi. Sekam padi yang sudah benarbenar kering dan telah memiliki massa yang konstan, selanjutnya di pra-karbonisasi. Proses prakarbonisasi dilakukan dengan menggunakan oven listrikpada suhu $200^{\circ}$ Cselama 3 jam. Setelah proses pra-karbonisasi karbon digerus dan diayak menggunakan ayakan 100 mesh hingga dihasilkan produk serbuk karbon swa-merekat (SKSM).
SKSM selanjutnya di aktivasi yang bertujuan untuk memperbanyak pori dan memperbesar luas permukaan karbon aktif sehingga daya serap karbon aktif akan meningkat. Aktivasi yang dilakukan yaitu dengan proses aktivasi kimia menggunakan aktivator kalium hidroksida $(\mathrm{KOH})$. Aktivasi kimia dilakukan dengan menggunakan gelas beakeryang diisi air suling sebanyak $300 \mathrm{~mL}$, selanjutnya ditambahkan padatan $\mathrm{KOH}$ sebanyak $5 \%, 10 \%, 15 \%$ dan $20 \%$ dari berat SKSM, kemudian perlahan-lahan masukkan SKSM sebanyak 30 gram. Aduk larutan menggunakan stirring hotplate dan magnetic stirrer pada suhu ruang $\left(30^{\circ} \mathrm{C}\right)$ dengan kecepatan pengadukan 400 rpm selama 20 jam.Tutup gelas beaker dengan menggunakan alumunium foil. Karbon aktif yang telah di aktivasi kimia kemudian dilakukan proses iradiasi gelombang mikro menggunakan oven microwavedengan daya 450 watt selama 15 menit. Tahap terakhir pembuatan karbon aktif dari sekam padi yaitu proses pencucian dan pengeringan. Tahap pencucian dilakukan dengan cara merendam karbon aktif dengan air suling, pencucian karbon aktif dilakukansecara berulang-ulang hingga mencapai $\mathrm{pH}$ netral $(\mathrm{pH}$ 7). Pengujian nilai $\mathrm{pH}$ menggunakan kertas lakmus yang dilakukan setiap penggantian air suling sampai $\mathrm{pH} \sim 7$.Karbon aktif dengan $\mathrm{pH}$ netral kemudian dikeringkan menggunakan oven dengan suhu $100^{\circ} \mathrm{C}$ selama 24 jam.

\section{HASIL DAN PEMBAHASAN}

Karakterisasi karbon aktif dilakukan untuk mengetahui yield karbon aktif, morfologi permukaan, dan daya serap karbon aktif terhadap logam berat berat yang terdapat pada pesisir air laut Dumai.

\section{Hasil pra-karbonisasi karbon aktif sekam padi}

Proses pra-karbonisasi menyebabkan perubahan warna sekam padi yang disebabkan 
senyawa-senyawa kompleks yang menyusun material organik terurai menjadi arang dengan kandungan unsur karbon yang tinggi [7]. Sekam padi sebelum melalui proses pra-karbonisasi berwarna kuning keemasan, sementara sekam padi yang telah melalui proses pra-karbonisasi berubah warna menjadi coklat kehitaman. Hasil prakarbonisasi dapat dilihat pada Gambar 4.1.

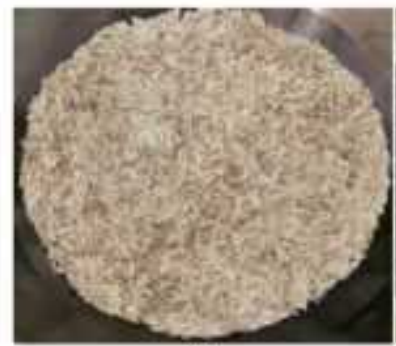

(a)

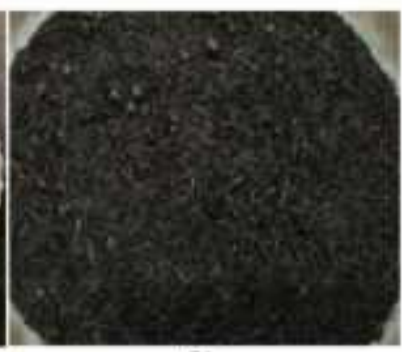

(b)
Gambar 1. Sekam Padi (a) Sebelum PraKarbonisasi dan (b) Setelah Pra-Karbonisasi.

Proses pra-karbonisasi juga menyebabkan penyusutan masssa sekam padi. Tabel 4.1 menunjukkan bahwa rata-rata penyusutan massa sekam sekam padi setelah proses pra-karbonisasi sebesar 39,03\% dari massa awal sampel. Sekam padi yang di pra-karbonisasi mengalami penyusutan massa karena hilangnya kandungan air pada sampel dan terurainya material organik seperti hemiselulosa, selulosa dan lignin menjadi unsur karbon [8].

Tabel 1. Penyusutan massa sekam padi pada proses pra-karbonisasi.

\begin{tabular}{cccc}
$\begin{array}{c}\text { Pra- } \\
\text { Karbonisasi } \\
\text { ke- }\end{array}$ & $\begin{array}{c}\text { Massa } \\
\text { Sekam } \\
\text { Padi } \\
\text { Sebelum } \\
\text { (gram) }\end{array}$ & $\begin{array}{c}\text { Massa } \\
\text { Sekam } \\
\text { Padi } \\
\text { Setelah } \\
\text { (gram) }\end{array}$ & $\begin{array}{c}\text { Penyusutan } \\
\text { Massa } \\
(\%)\end{array}$ \\
\hline 1 & 30 & 19,90 & 33,66 \\
2 & 30 & 20,15 & 32,83 \\
3 & 30 & 18,86 & 37,13 \\
4 & 30 & 18,32 & 38,93 \\
5 & 30 & 15,65 & 47,83 \\
6 & 30 & 16,85 & 43,83 \\
\hline
\end{tabular}

\section{Yield karbon aktif}

$\mathrm{KOH}$ digunakan sebagai aktivator karena dapat bereaksi dengan karbon dan bisa menghilangkan zat-zat pengotor dalam karbon sehingga membuat karbon menjadi lebih berpori yang akan berpengaruh pada daya serapnya [9]. Proses selanjutnya yaitu iradiasi gelombang mikro dengan daya 450 Watt selama 15 menit dapat menghilangkan kadar air dan membentuk pori karbon aktif secara maksimum [10]. Karbon aktif sebelum dan setelah dilakukan iradiasi gelombang mikro ditimbang untuk mendapatkan nilai yield karbon aktif. Yield karbon aktif dengan variasi persentase KOH untuk sampel KA5, KA10, KA15 dan KA20 dapat dilihat pada Gambar 1.

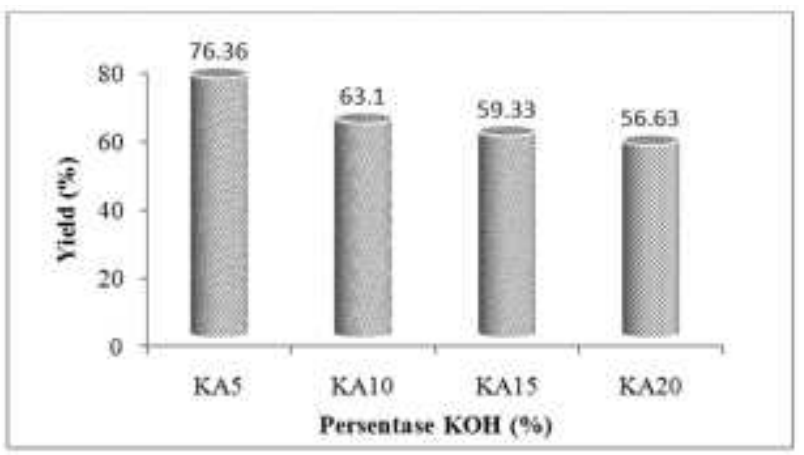

Gambar 2. Yield karbon aktif.

Gambar 1 menunjukkan yield karbon aktif untuk masing-masing sampel dimana semakin tinggi persentase $\mathrm{KOH}$ maka yield karbon aktif akan semakin rendah. Menurut [11] penggunaan $\mathrm{KOH}$ selama proses aktivasi menghasilkan degradasi material yang akan membentuk pori. Semakin besar persentase $\mathrm{KOH}$ maka semakin besar degradasi material yang terjadi sehingga nilai yield karbon aktifakan semakin menurun.

\section{Analisa Scanning Electron Microscopy}

Morfologi permukaan karbon aktif sekam padi dapat diketahui dengan cara melihat bentuk permukaan, ukuran dan distribusi pori dengan menggunakan Scanning Electron microscopy 
(SEM). Gambar2 menunjukkan morfologi permukaan karbon aktif sekam padiuntuk setiap variasi persentase $\mathrm{KOH}$.

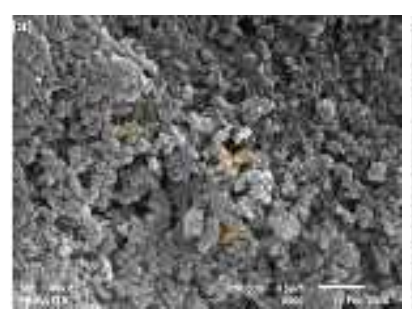

(a)

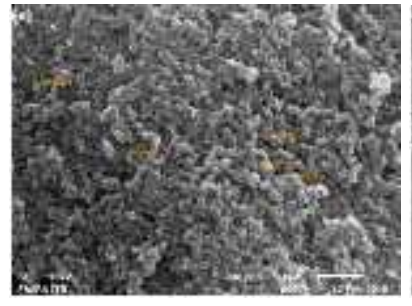

(c)

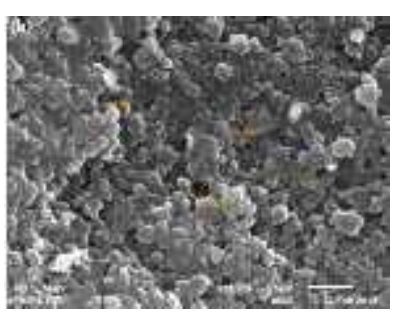

(b)

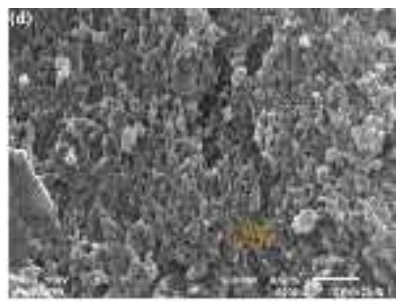

(d)
Gambar 3. Hasil SEM dengan Perbesaran 3000x (a) KA5 (b) KA10(c) KA15 (d) KA20.

Gambar 2(a) menampilkan morfologi permukaan sampel KA5, dimana pori-pori yang dihasilkan memiliki struktur pori yang tidak teratur dengan jumlah pori yang lebih sedikit karena masih tertutup oleh zat-zat pengotor. Gambar 2(b) menampilkan morfologi permukaan sampel KA10 yang memiliki struktur pori yang lebih teratur daripada sampel KA5 dengan jumlah pori-pori yang lebih banyak dibandingkan sampel KA5. Gambar 2(c) menampilkan morfologi permukaan sampel KA15 dimana terlihat pori-pori karbon aktifnya semakin kecil dan sedikit, hal ini dikarenakan saat pengaktifan menggunakan iradiasi gelombang mikro sampel KA15 terbakar sehingga pembentukan pori tidak maksmial. Gambar 2(d) menampilkan morfologi permukaan sampel KA20, dimana pori-pori yang dihasilkan juga sedikit karena masih terdapat kandungan zat pengotor pada sampel karbon aktif, selain itu disebabkan juga penggunaan aktivator $\mathrm{KOH}$ yang berlebih sehingga menyebabkan pori-pori karbon aktif yang terbentuk menjadi rusak [12].

Pori-pori karbon aktif yang dihasilkan pada sampel KA5, KA10 dan KA15 tergolong ke dalam makropori dimana diameter porinya berturut-turut adalah $0,148 \mu \mathrm{m}, \quad 0,173 \mu \mathrm{m}$ dan $0,064 \mu \mathrm{m}$, sedangkansampel KA20 tergolong ke dalam mesopori dengan diameter pori $0,041 \mu \mathrm{m}$. Hasil karakterisasi SEM menunjukkan sampel KA10 memiliki luas permukaan terbesar dengan jumlah pori-pori yang banyak.

\section{Analisa daya serap karbon aktif}

Daya serap karbon aktif dapat diketahui dengan cara mengetahui persentase logam berat sebelum dan sesudah diberikan karbon aktif menggunakan alat spektroskopi serapan atom (SSA).Logam berat yang akan di ukur yaitu logam $\mathrm{Ni}, \mathrm{Pb}$, dan $\mathrm{Zn}$ yang terdapat pada air laut Dumai dengan konsentrasi awal 1,250 ppm untuk logam $\mathrm{Ni}, 1,530$ ppm untuk logam $\mathrm{Pb}$ dan 0,551 untuk logam Zn. Besar konsentrasi logam berat setelah diberikan karbon aktif untuk setiap variasi persentase $\mathrm{KOH}$ dapat dilihat pada Tabel 1.

Tabel 2.Konsentrasi Logam Berat pada Air Laut Dumai Setelah Diberikan Karbon Aktif.

\begin{tabular}{|c|c|c|c|c|c|c|}
\hline $\mathrm{S}$ & \multicolumn{6}{|c|}{ Logam Berat } \\
\hline $\begin{array}{l}\mathrm{m} \\
\mathrm{p} \\
\mathrm{el}\end{array}$ & $\begin{array}{c}\mathrm{Ni} \\
(\mathrm{ppm})\end{array}$ & $\begin{array}{c}\text { Daya } \\
\text { Serap } \\
(\%)\end{array}$ & $\begin{array}{c}\mathrm{Pb} \\
(\mathrm{ppm})\end{array}$ & $\begin{array}{c}\text { Daya } \\
\text { Serap } \\
(\%)\end{array}$ & $\begin{array}{c}\mathrm{Zn} \\
(\mathrm{ppm})\end{array}$ & $\begin{array}{c}\text { Daya } \\
\text { Serap } \\
(\%)\end{array}$ \\
\hline $\begin{array}{l}\mathrm{K} \\
\mathrm{A}\end{array}$ & 0,284 & 76,88 & 0,172 & 88,75 & 0,551 & 69,87 \\
\hline $\begin{array}{l}\mathrm{K} \\
\mathrm{A}\end{array}$ & 0,095 & 92,40 & 0,133 & 91,31 & 0,166 & 70,24 \\
\hline $\begin{array}{l}\mathrm{K} \\
\mathrm{A}\end{array}$ & 0,318 & 74,56 & 0,203 & 86,73 & 0,167 & 69,69 \\
\hline $\begin{array}{l}\mathrm{K} \\
\mathrm{A}\end{array}$ & 0,389 & 68,88 & 0,231 & 84,90 & 0,212 & 61,52 \\
\hline
\end{tabular}

Konsentrasi logam berat yang terdapat pada air laut Dumai menurun setelah diberikan karbon aktif. Sampel KA10 memiliki konsentrasi logam berat 
yang paling rendah, yaitu 0,095 untuk logam $\mathrm{Ni}$, 0,133 untuk logam $\mathrm{Pb}$ dan 0,164 untuk logam $\mathrm{Zn}$, sedangkan sampel KA20 merupakan sampel dengan konsentrasi logam berat tertinggi, yaitu 0,389 untuk logam Ni, 0,231 untuk logam $\mathrm{Pb}$ dan 0,212 untuk logam $\mathrm{Zn}$.

Persentase daya serap yang paling tinggi adalah pada sampel KA10 dengan daya serap sebesar 92,40\% untuk logam $\mathrm{Ni}, 91,31 \%$ untuk logam $\mathrm{Pb}$ dan 70,24\% untuk logam $\mathrm{Zn}$. Daya serap yang paling rendah dihasilkan oleh sampel KA20 dengan daya serap sebesar $68,88 \%$ untuk $\operatorname{logam~Ni}$, $84,90 \%$ untuk logam $\mathrm{Pb}$ dan $61,52 \%$ untuk logam Zn. Hal ini menandakan bahwa pemberian persentase $\mathrm{KOH}$ yang optimum berada pada sampel KA10, sedangkan pada sampel KA15 dan KA20 efisiensi adsorpsi menurun yang disebabkan oleh penggunaan persentase aktivator $\mathrm{KOH}$ yang berlebih sehingga aktivasi karbon aktif tidak terjadi secara maksimal [11]. Berdasarkan Tabel 1 dapat dibuat grafik antara persentase daya serap karbon aktif dan persentase $\mathrm{KOH}$ seperti yang ditunjukkan pada Gambar 3.

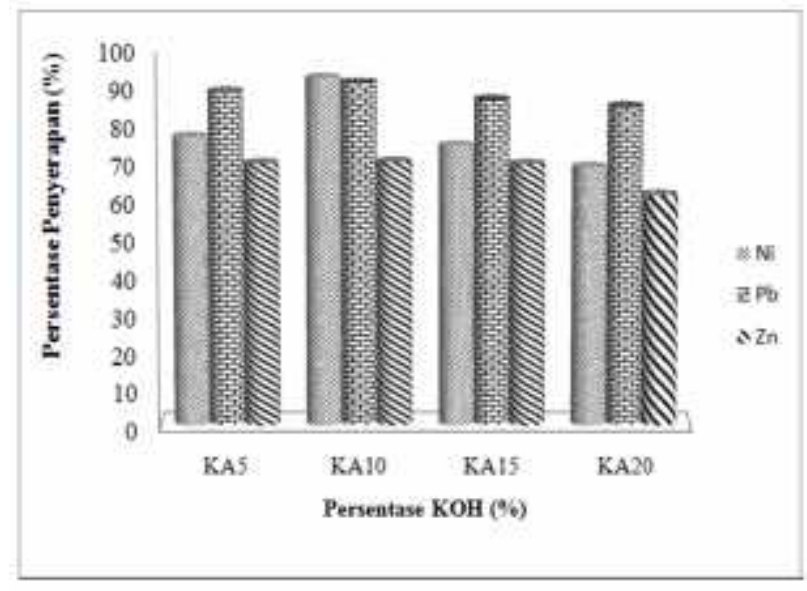

Gambar 4.Persentase Penyerapan Logam Berat.

Besar daya serap karbon aktif yang didapat pada penelitian ini tidak jauh berbeda dengan penelitian Erlina et al., (2015) yang membuat karbon aktif dari tempurung kelapa menggunakan aktivator $\mathrm{KOH}$ dengan besar persentase penyerapan $83,57 \%$.

\section{KESIMPULAN}

Karbon aktif dari sekam padi telah berhasil dibuat dengan proses pra-karbonisasi, aktivasi kimia menggunakan $\mathrm{KOH}$ dengan variasi persentase $5 \%$, $10 \%, 15 \%$ dan $20 \%$ dari massa karbon aktif dan dengan bantuan iradiasi gelombang mikro. Analisa morfologi permukaan karbon aktif menunjukkan bahwa sampel KA10 mempunyai pori-pori yang lebih teratur dan lebih banyak dibandingkan sampel KA5, KA15 dan KA20. Daya serap karbon aktif terhadap logam berat menunjukkan bahwa sampel KA10 mempunyai daya serap yang lebih baik dengan persentase daya serap sebesar 92,40\% untuk logam $\mathrm{Ni}, 91,31 \%$ untuk logam $\mathrm{Pb}$ dan 70,24\% untuk logam Zn.

\section{DAFTAR PUSTAKA}

1. Syakti, A. D., Hidayati, N. V., \& Siregar, A. S. (2012). Agen Pencemaran Laut. Bogor : IPB Press.

2. Siregar, Y. \& Edward, J. (2010). Faktor Konsentrasi $\mathrm{Pb}, \mathrm{Cd}, \mathrm{Cu}, \mathrm{Ni}, \mathrm{Zn}$ dalam Sedimen Perairan Pesisir Kota Dumai. Jurnal Ilmu Kelautan, FPIK, UR., 1, 1-10.

3. Suprihatin \& Suparno, O. (2013). Teknologi Proses Pengolahan Air untuk Mahasiswa dan Praktisi Industri. Bogor: IPB Press.

4. Tirono, M. \& Sabit, A. (2011). Efek Suhu pada Proses Pengarangan terhadap Nilai Kalor Arang Tempurung Kelapa (Coconut Shell Charcoal). Jurnal Neutrino, 3, 143-152.

5. Siahaan, S., Hutapea, M., \& Hasibuan, R. (2013). Penentuan Kondisi Optimum Suhu dan Waktu Karbonisasi pada Pembuatan Arang Sekam Padi. Jurnal Teknik Kimia USU., 2(1), 26-30. 
6. Wannapeera, J., Worasuwannarak, N., \& Pipatmanomai, S. (2008). Product Yields and Characteristics of Rice Husk, Rice Straw and Corncob during Fast Pyrolysis in a Droptube/Fixed-bed Reactor. Songklanakarin Journal of Science and Technology, 30(3), 393-404.

7. Destyorini, F., Suhandi, A., Subhan, A., \& Indayaningsih N. (2010). Pengaruh Suhu Karbonisasi terhadap Struktur dan Konduktivitas Listrik Arang Serabut Kelapa. Jurnal Himpunan Fisika Indonesia, 10(2), 122132.

8. Bangun, T. A., Zaharah, T. A., \& Shofiyani A. (2016). Pembuatan Arang Aktif dari Cangkang Buah Karet untuk Adsorpsi Ion Besi (II) dalam Larutan. JKK UNTAN, 5(3), 18-24.

9. Apriani, R., Faryuni, I. D., \& Wahyuni, D. (2013). Pengaruh Konsentrasi Aktivator Kalium Hidroksida $(\mathrm{KOH})$ terhadap Kualitas Karbon Aktif Kulit Durian sebagai Adsorben Logam Fe pada Air Gambut. Jurnal Prisma Fisika, 1(2), 82-86.
10. Ahmed, M. J. \& Theydan, S. K. (2014). Optimibahanion of Microwave Preparation Conditions for Activated Carbon fomAlbiziaLebbeck Seed Pods for Methylene Blue Dye Adsorption. Journal of Analytical and Applied Pyrolysis, 105, 199-208.

11. Erlina, U., \& Budi, E. (2015). Pengaruh Konsentrasi Larutan $\mathrm{KOH}$ pada Karbon Aktif Tempurung Kelapa untuk Adsorpsi Logam Cu. Jurnal Fisika UNJ., 4, 55-60.

12. Santoso, R. H., Susilo, B., \& Nugroho, A. N. (2014). Pembuatan dan Karakterisasi Karbon Aktif dari Kulit Singkong (Manihotescula Crantz) menggunakan Activating Agent $\mathrm{KOH}$. Jurnal Keteknikan Tropis dan Biosistem, 2(3), 279-286. 